\title{
GLUT2 protein at the rat proximal tubule brush border membrane correlates with protein kinase $C$ (PKC)- $\beta I$ and plasma glucose concentration
}

\author{
A. K. Goestemeyer • J. Marks • S. K. Srai • \\ E. S. Debnam • R. J. Unwin
}

Received: 1 April 2007 / Accepted: 21 June 2007 /Published online: 11 August 2007

(C) Springer-Verlag 2007

\begin{abstract}
Aims/hypothesis GLUT2 is the main renal glucose transporter upregulated by hyperglycaemia, when it becomes detectable at the brush border membrane (BBM). Since glucoseinduced protein kinase $\mathrm{C}$ (PKC) activation in the kidney is linked to diabetic nephropathy, we investigated the effect of glycaemic status on the protein levels of PKC isoforms $\alpha, \beta \mathrm{I}$, $\beta$ II, $\delta$ and $\varepsilon$ in the proximal tubule, as well as the relationship between them and changes in GLUT2 production at the BBM. Methods Plasma glucose concentrations were modulated in rats by treatment with nicotinamide $15 \mathrm{~min}$ prior to induction of diabetes with streptozotocin. Levels of GLUT2 protein and $\mathrm{PKC}$ isoforms in BBM were measured by western blotting. Additionally, the role of calcium signalling and PKC activation on facilitative glucose transport was examined by measuring glucose uptake in BBM vesicles prepared from proximal tubules that had been incubated either with thapsigargin, which increases cytosolic calcium, or with the PKC activator phorbol 12myristate, 13-acetate (PMA).
\end{abstract}

A. K. Goestemeyer and J. Marks contributed equally to the study.

A. K. Goestemeyer · J. Marks $(\bowtie) \cdot$ E. S. Debnam • R. J. Unwin

Department of Physiology, Royal Free and University

College Medical School, Hampstead Campus,

Rowland Hill Street,

London NW3 2PF, UK

e-mail: j.marks@medsch.ucl.ac.uk

S. K. Srai

Department of Biochemistry \& Molecular Biology,

Royal Free and University College Medical School,

London, UK

R. J. Unwin

Centre for Nephrology,

Royal Free and University College Medical School,

London, UK
Results Thapsigargin and PMA enhanced GLUT-mediated glucose uptake, but had no effect on sodium-dependent glucose transport. Diabetes significantly increased the protein levels of GLUT2 and PKC- $\beta$ I at the BBM. Levels of GLUT2 and PKC- $\beta$ I correlated positively with plasma glucose concentration. Diabetes had no effect on BBM levels of $\alpha, \beta \mathrm{II}, \delta$ or $\varepsilon$ isoforms of PKC.

Conclusions/interpretation Enhanced GLUT2-mediated glucose transport across the proximal tubule BBM during diabetic hyperglycaemia is closely associated with increased PKC- $\beta$ I. Thus, altered levels of GLUT2 and PKC- $\beta$ I proteins in the BBM may be important factors in the pathogenic processes underlying diabetic renal injury.

Keywords Brush border membrane $\cdot$ Diabetes .

Facilitated glucose transporters - GLUT2 - Hyperglycaemia .

Protein kinase C $\cdot$ Proximal tubule $\cdot$ Streptozotocin

$\begin{array}{ll}\text { Abbreviations } \\ \text { BBM } & \text { brush border membrane } \\ K_{\mathrm{t}} & \text { glucose concentration at half } V_{\max } \\ \text { PBS-T } & \text { PBS containing } 0.1 \% \text { Tween } 20 \\ \text { PKC } & \text { protein kinase C } \\ \text { PMA } & \text { phorbol 12-myristate, } 13 \text {-acetate } \\ \text { SGLT } & \text { sodium/glucose cotransporter } \\ \text { STZ } & \text { streptozotocin } \\ V_{\max } & \text { maximum transport capacity }\end{array}$

\section{Introduction}

In the past decade significant advances have been made in defining the cellular mechanisms involved in diabetesinduced renal injury. Data from clinical trials and experimental models of diabetes have shown a strong correlation 
between hyperglycaemia and the development and progression of diabetic nephropathy [1]. Most studies have concentrated on the effect of high glucose concentrations on mesangial cells, since glomerulopathy is the most characteristic clinical and histological feature of diabetic renal disease. These studies have provided convincing evidence that overproduction of GLUT1 and protein kinase C (PKC)- $\beta \mathrm{I}$ are linked to glucose-induced mesangial cell damage and extracellular matrix deposition $[1,2]$. Diabetes also increases renal size, mainly due to proximal tubular cell hypertrophy and thickening of the tubular cell basement membrane [3], leading to eventual tubular cell loss and declining renal function [4]; however, the underlying mechanisms affecting proximal tubular cell function and their relationship to glucose transport have not been studied in any detail.

In the last 5 years, the conventional model of glucose transport across renal and intestinal epithelia has been challenged. It is now clear that sodium/glucose cotransporters (SGLTs) and GLUT2 work in conjunction to transport glucose across the brush border membrane (BBM) over a wide range of glucose concentrations. The proposed model for enterocyte glucose uptake is that a high level of luminal glucose leads to rapid insertion of GLUT2 into the BBM via a calcium- and PKC- $\beta$ II-dependent mechanism [5-8]. There is less evidence to support a similar process occurring in the proximal tubule BBM, but because the basic glucose transport mechanisms are similar in both tissues, it seems likely that the same model may apply. Indeed, we have demonstrated that GLUT2 is translocated to the proximal tubule BBM in streptozotocin (STZ)-induced diabetes and that overnight fasting, which reduces plasma glucose concentrations to normal levels, reverses the BBM targeting of GLUT2 [9].

Previous studies have shown that many PKC isoforms are present in rat and mouse kidneys. Immunohistochemistry has localised different isoforms to specific nephron segments, and there are also distinct species differences. In rat kidney, the PKC isoforms $\alpha, \beta \mathrm{I}, \beta \mathrm{II}, \delta, \varepsilon$ and $\zeta$ have been detected in the proximal tubule [10] with prominent staining for PKC- $\alpha[11,12]$ and $-\beta I[12]$ at the BBM. In contrast, $\mathrm{PKC}-\alpha$ and $-\beta$ isoforms are undetectable in mouse proximal tubules, with $\mathrm{PKC}-\varepsilon$ being the predominant isoform in this species [13]. Studies have also detected altered levels of PKC isoforms in proximal tubular cells following exposure to high glucose concentrations, e.g. PKC- $\alpha,-\varepsilon[10]$ and $-\beta$ I [14] specifically were found to be increased. These findings suggest that diabetes-induced alterations in the levels and activity of PKC isoforms may affect proximal tubular cell function, as well as having their already established effects on glomerular cells.

Since GLUT1 and PKC- $\beta 1$ may influence mesangial cell size in diabetes [1], and also due to the fact that PKC- $\beta$ II regulates GLUT2 protein levels at the enterocyte BBM, we investigated the relationship between changes in circulating glucose concentration and protein levels of PKC- $\beta$ I, PKC$\beta I I$ and other PKC isoforms, together with GLUT2 abundance at the proximal tubule BBM. In order to study as wide a range of glucose concentrations as possible, we used normal animals and STZ-diabetic animals, with or without prior treatment with low or high doses of nicotinamide. Nicotinamide protects pancreatic beta cells from STZ cytotoxicity [15] and makes it possible to modulate blood glucose concentrations more effectively than by using graded doses of STZ.

\section{Methods}

Animals The present study used $250 \mathrm{~g}$ male SpragueDawley rats bred in the Comparative Biology Unit at the Royal Free and University College Medical School. Two weeks prior to use animals received a single i.p. injection of nicotinamide dissolved in sterile saline $(0,50$ and $200 \mathrm{mg} /$ $\mathrm{kg}$ ), followed 15 min later by a single tail vein injection of STZ $(60 \mathrm{mg} / \mathrm{kg})$ dissolved in freshly prepared citrate buffer $(\mathrm{pH} 4.5)$ under halothane anaesthesia $(2 \%$ halothane in $100 \%$ oxygen). Animals were allowed free access to water and a standard rat chow (Diet RM1; SDS, Witham, Essex, UK) until the time of experimentation, except for those which were fasted overnight prior to killing. All procedures were carried out in accordance with the UK Animals (Scientific Procedures) Act 1986. Plasma glucose concentrations were determined using a glucose oxidase method.

Brush border membrane vesicle preparation The methods used to prepare renal BBM vesicles have been described previously [9]. In brief, animals were anaesthetised with an i.p. injection of $60 \mathrm{mg} / \mathrm{kg}$ pentobarbitone sodium (Pentoject, Animalcare, York, UK) and both kidneys removed and placed in ice-cold $154 \mathrm{mmol} / \mathrm{l} \mathrm{NaCl}$. After removal of the renal capsule, the kidneys were weighed, sliced into $2 \mathrm{~mm}$ sections and the cortex dissected away. Cortical fragments were suspended in $30 \mathrm{ml}$ of buffer containing (mmol/l) 300 mannitol, 12 Tris $\mathrm{HCl}, 5$ EGTA, pH 7.4. The resulting suspension was homogenised for 2 min (Ultra Turrax homogeniser; Janke \& Kunkel, IKA Labortechnik, Staufen, Germany) at half speed, followed by the addition of $42 \mathrm{ml}$ of cold distilled water and $\mathrm{MgCl}_{2}$ to a concentration of $12 \mathrm{mmol} / \mathrm{l}$; it was then stirred on ice for $15 \mathrm{~min}$. The solution was then centrifuged for $15 \mathrm{~min}$ at $2,000 \times \mathrm{g}$ and the supernatant fraction recentrifuged for $30 \mathrm{~min}$ at $21,000 \times \mathrm{g}$. The pellet was suspended in $20 \mathrm{ml}$ buffer containing (mmol/l): 150 mannitol, 6 Tris $\mathrm{HCl}, 2.5$ EGTA (pH 7.4) using ten cycles of a hand-operated glass-Teflon homogeniser. $\mathrm{MgCl}_{2}$ was added to a concentration of $12 \mathrm{mmol} / \mathrm{l}$ and, after stirring on ice for $15 \mathrm{~min}$, the low and high-speed centrifugations described above were repeated. 
The pellet was then resuspended in $20 \mathrm{ml}$ buffer containing (mmol/l) 300 mannitol, 12 Tris $\mathrm{HCl}, 2.5$ EGTA (pH 7.4) and centrifuged at $21,000 \times g$ for $30 \mathrm{~min}$. The purified BBM pellet was finally suspended in the same buffer to a protein concentration of 3 to $6 \mathrm{mg} / \mathrm{ml}$ using five to six passes through a syringe fitted with a 21-gauge needle. All steps were carried out at $4{ }^{\circ} \mathrm{C}$. The concentration of protein and activity of alkaline phosphatase in the initial homogenate and BBM preparation were determined to derive values for enrichment of this marker enzyme.

Proximal tubule exposure to thapsigargin and phorbol 12myristate,13-acetate Cortical fragments (prepared as above) from six kidneys were divided into two equal samples and were suspended in $30 \mathrm{ml}$ buffer containing (mmol/1) 300 mannitol, 12 Tris HCl, 5 EGTA, pH 7.4. A suspension was then obtained by subjecting the solution to six strokes in a hand-held glass-Teflon homogeniser. Paired incubations were carried out by adding $1 \mu \mathrm{mol} / 1$ phorbol 12-myristate, 13 -acetate (PMA) or $1 \mu \mathrm{mol} / 1$ thapsigargin dissolved in DMSO to one-half of the suspension, while the other half received an equal volume of DMSO. Suspensions were incubated at $37^{\circ} \mathrm{C}$ in a shaking water-bath, while being gassed with $100 \%$ oxygen. After $30 \mathrm{~min}$, tubules were separated by centrifugation ( $2 \mathrm{~min}$ at $40 \times g$ ) and BBM vesicles were prepared from the precipitate as described above.

Brush border membrane uptake studies Uptake studies were carried out at $20^{\circ} \mathrm{C}$ on freshly prepared vesicles as described for intestinal BBM [16]. In brief, the transport process was initiated by mixing equal volumes of vesicle suspension and uptake buffer consisting of (in mmol/l) 200 NaSCN, 20 HEPES, $0.1 \mathrm{MgSO}_{4}$ containing $\mathrm{D}-\left[{ }^{3} \mathrm{H}\right]$ glucose, such that the final concentration of glucose was 30 to $960 \mu \mathrm{mol} / \mathrm{l}$. Uptake was terminated after $4 \mathrm{~s}$ by the addition of $3 \mathrm{ml}$ of $154 \mathrm{mmol} / 1 \mathrm{NaCl}$ containing $0.5 \mathrm{mmol} / 1$ phlorizin maintained at $4^{\circ} \mathrm{C}$, followed by vacuum filtration through $0.45 \mu \mathrm{m}$ nitrocellulose filters (Sartorius, Göttingen, Germany). Three further washes were carried out. Parallel uptakes using buffer containing $1 \mathrm{mmol} / \mathrm{l}$ phlorizin to block SGLT-mediated transport indicated that uptake was $>96 \%$ phlorizin-sensitive. In order to assess GLUT-mediated transport, a higher glucose concentration $(20 \mathrm{mmol} / \mathrm{l})$ was used in the presence of $1 \mathrm{mmol} / 1$ phlorizin, in keeping with the low affinity of GLUT transporters for glucose binding [17]. From scintillation counting of the filters, BBM glucose accumulation was calculated and expressed as nmol mg protein ${ }^{-1} 4 \mathrm{~s}^{-1}$. The kinetic parameters of maximum transport capacity $\left(V_{\max }\right)$ and glucose concentration at half $V_{\max }\left(K_{\mathrm{t}}\right)$ for phlorizin-sensitive uptake were derived using a non-linear least squares curve-fitting program (GraphPad Software, San Diego, CA, USA).
Western blotting Polyclonal antibodies for GLUT2 and the PKC isoforms ( $\alpha, \beta$ I, $\beta$ II, $\delta$ and $\varepsilon$ ) were purchased from Biogenesis (Poole, UK) and Santa Cruz Biotechnology (Santa Cruz, CA, USA), respectively. For western blotting, BBM samples (15 $\mu \mathrm{g}$ protein) were solubilised in Laemmli sample buffer containing 5\% SDS and 5\% mercaptoethanol, and electrophoresed on a $10 \%$ SDS polyacrylamide gel. The proteins were transferred to nitrocellulose membranes by semi-dry electrophoretic blotting for $1 \mathrm{~h}$ at a constant current of $1 \mathrm{~mA} / \mathrm{cm}^{2}$. Non-specific protein-binding sites were blocked with PBS containing $0.1 \%$ Tween 20 (PBS-T) and 5\% fat-free milk for $1 \mathrm{~h}$ at room temperature. The membranes were incubated with GLUT2 (1:1000), PKC- $\alpha$ (1:400), PKC- $\beta$ I (1:200), PKC- $\beta$ II $(1: 200)$, PKC- $\delta$ $(1: 500)$ and PKC- $\varepsilon(1: 500)$ antibodies for $16 \mathrm{~h}$ at $4^{\circ} \mathrm{C}$. The filters were then washed $(2 \times 15 \mathrm{~min})$ with PBS-T containing $1 \%$ fat-free milk and incubated for $2 \mathrm{~h}$ at room temperature with either anti-rabbit $(1: 2,000)$ (Amersham Pharmacia Biotech UK, Little Chalfont, UK) or anti-mouse (1:5,000) (Sigma, Poole, Dorset, UK) IgG antibody conjugated to horseradish peroxidase and finally washed again with PBS-T. Bound antibodies were detected using a western blot detection kit (Visualizer; Upstate Cell Signalling Solutions, Dundee, UK) and visualised and quantified using a Fluor-S MultiImager System (Biorad, Hemel Hempstead, UK). The abundance of GLUT2 relative to total protein concentration was established for each sample and expressed as a percentage of the control.

Statistics Data are presented as mean \pm SEM of six animals per experimental group. Normal distribution was determined by Kolmogrov-Smirnov test of normality and statistical comparisons made using either an unpaired $t$ test or a one-way ANOVA with post hoc comparisons performed using either the Bonferroni multiple comparisons test or the Kruskal-Wallis test. All analyses were performed using Graphpad Instat software (GraphPad Software) with statistical significance taken as $p<0.05$.

\section{Results}

Animals treated with STZ alone gained less weight over the 2 week experimental period than control animals. In contrast, animals receiving 50 or $200 \mathrm{mg} / \mathrm{kg}$ nicotinamide prior to STZ gained weight at the same rate as control animals (Table 1). Kidney weight was significantly increased following STZ injection, but not when animals were pretreated with nicotinamide (Table 1). Animals receiving STZ alone showed a 2.8-fold increase in plasma glucose concentration compared with control (Fig. 1); those pretreated with low dose nicotinamide $(50 \mathrm{mg} / \mathrm{kg})$ had 
Table 1 Effect of STZ and nicotinamide on animal weight gain, kidney weight and enrichment of alkaline phosphatase in BBM vesicles

\begin{tabular}{lllll}
\hline Parameter & Control & STZ & STZ $+50 \mathrm{mg} / \mathrm{kg}$ nicotinamide & STZ $+200 \mathrm{mg} / \mathrm{kg}$ nicotinamide \\
\hline Weight gain $(\mathrm{g})$ & $63.3 \pm 8.1$ & $24.0 \pm \pm^{`} 6.1^{*}$ & $57.3 \pm 5.85$ & $59.5 \pm 4.37$ \\
Kidney weight (mg kidney/g body weight) & $3.95 \pm 0.16$ & $5.24 \pm 0.1 * *$ & $4.00 \pm 0.18$ & $3.63 \pm 0.08$ \\
BBM enrichment & $11.35 \pm 0.65$ & $13.09 \pm 0.45$ & $12.3 \pm 0.99$ & $11.68 \pm 0.7$ \\
\hline
\end{tabular}

Values are mean $\pm \operatorname{SEM}(n=12-18)$

${ }^{*} p<0.05, * * * p<0.001$ compared with control using ANOVA with Tukey-Kramer post hoc test

plasma glucose levels 1.85 -fold greater than controls, whereas high dose nicotinamide $(200 \mathrm{mg} / \mathrm{kg})$ resulted in plasma glucose levels similar to those of controls. Overnight fasting of each group also reduced plasma glucose concentrations to levels similar to those of non-fasted controls (Fig. 1).

BBM vesicles used for western blotting and uptake studies were enriched with the BBM marker enzyme alkaline phosphatase (Table 1). Treatment with STZ or nicotinamide had no significant effect on enrichment.

We have reported previously that STZ-induced diabetes results in translocation of GLUT2 protein to the BBM and that this is likely to be due to hyperglycaemia [9]. The present study aimed to determine whether more modest changes in plasma glucose concentration had any effect on GLUT2 levels at the BBM. Western blotting for GLUT2 protein in BBM vesicles prepared from animals treated with STZ alone and from those pretreated with $50 \mathrm{mg} / \mathrm{kg}$ nicotinamide revealed an increase in GLUT2 (Fig. 2). In STZ animals pretreated with $200 \mathrm{mg} / \mathrm{kg}$ nicotinamide, GLUT2 levels were similar to non-diabetic levels before and after overnight fasting.

Recent studies have described the involvement of PKC and calcium-dependent signalling pathways in the control of facilitative glucose transport in mesangial cells and intestinal

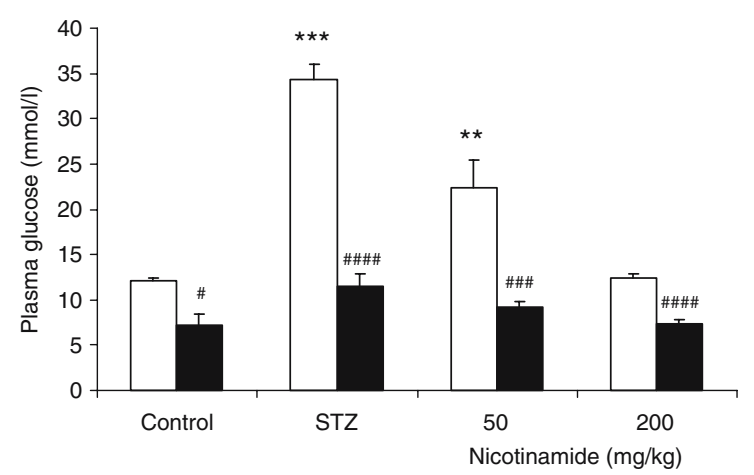

Fig. 1 Effect of STZ and nicotinamide on plasma glucose levels in non-fasted (open bars) and overnight fasted (closed bars) animals. Results are expressed as mean \pm SEM, $n=6-12$. ${ }^{* *} p<0.01, * * * p<$ 0.001 compared with non-fasted control animals using ANOVA with

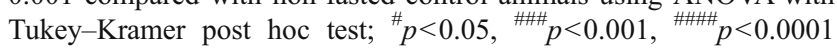
compared with non-fasted animals using unpaired $t$ test enterocytes $[1,6,18]$. In the present study, incubation of proximal tubules for $30 \mathrm{~min}$ with $1 \mu \mathrm{mol} / \mathrm{l} \mathrm{PMA}$, a PKC agonist, had no effect on the $V_{\max }$ or the $K_{\mathrm{t}}$ (control: $505 \pm 54$ vs PMA: $462 \pm 18 \mu \mathrm{mol} / \mathrm{l})$ of SGLT-mediated glucose transport (Fig. 3). In contrast, GLUT-mediated uptake was significantly enhanced by PMA (Fig. 3). Similar responses were observed following exposure of proximal tubules to $1 \mu \mathrm{mol} / 1$ thapsigargin (which releases $\mathrm{Ca}^{2+}$ from cellular stores): the $V_{\max }$ and $K_{\mathrm{t}}$ for SGLT-mediated uptake were unaffected $\left(K_{\mathrm{t}}\right.$ control: $431 \pm 47$ vs thapsigargin: $435 \pm$

\section{a}
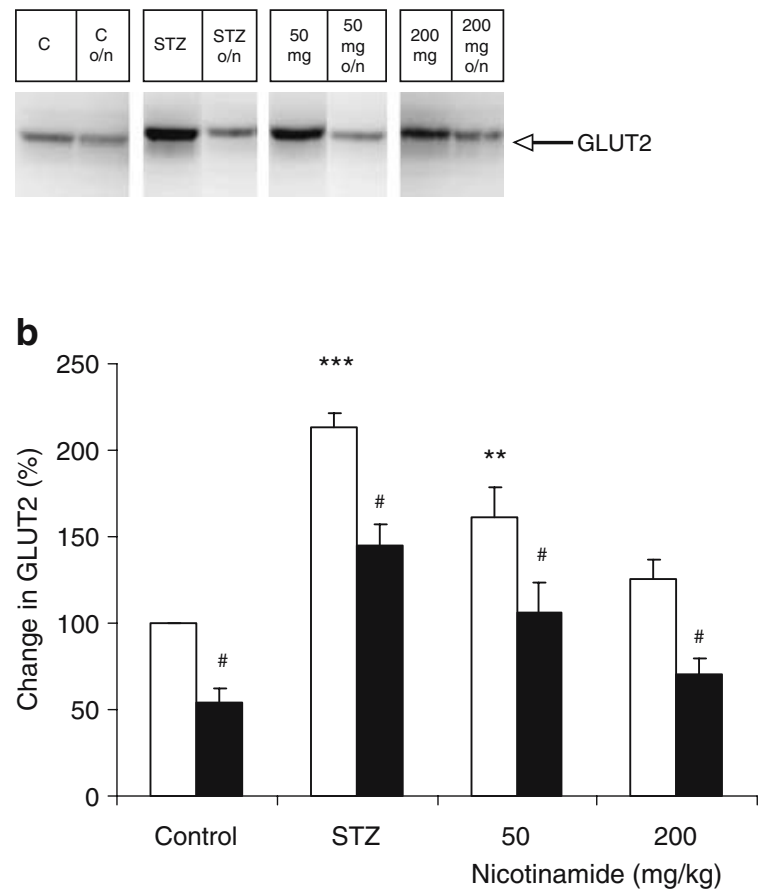

Fig. 2 a Representative western blot of GLUT2 in BBM vesicles of control and STZ-injected animals, with or without treatment with nicotinamide (centre right and right: 50 or $200 \mathrm{mg}$ ) or overnight $(\mathrm{o} / \mathrm{n}$ ) fasting. b Quantification of GLUT2 in BBM vesicles of non-fasted (open bars) and overnight fasted (closed bars) animals in the different experimental groups. Results are expressed as a percentage of GLUT2 compared with control, $n=6-12$. ${ }^{* *} p<0.01, * * * p<0.001$ compared with non-fasted control group using ANOVA with Dunn's multiple comparison post hoc test; ${ }^{\#} p<0.05$ compared with non-fasted animals using unpaired $t$ test 
$16 \mu \mathrm{mol} / \mathrm{l}$ ), whereas GLUT-mediated glucose uptake was significantly enhanced (Fig. 3).

Using western blotting, we examined the effects of STZdiabetes on levels of PKC- $\alpha,-\beta \mathrm{I},-\beta \mathrm{II},-\delta$ and $-\varepsilon$ protein in BBM vesicles. Diabetes had no effect on the levels of PKC$\beta \mathrm{II}, \alpha, \delta$ or $\varepsilon$, but levels of PKC- $\beta$ I were significantly increased (Fig. 4). We then examined the effect of smaller variations in blood glucose concentration on BBM levels of PKC- $\beta$ I. This was achieved by administering nicotinamide $15 \mathrm{~min}$ prior to STZ and by overnight (18 h) fasting of both non-diabetic and diabetic animals. Figure 5 shows that treatment with 50 and $200 \mathrm{mg} / \mathrm{kg}$ nicotinamide reduced PKC- $\beta$ I, while overnight fasting in all the groups decreased the protein to the levels found in control animals.

The relationship between plasma glucose concentration, GLUT2 and PKC- $\beta$ I was also examined by cross-correlating these three variables. It is clear that over the range of plasma glucose concentrations recorded, GLUT2 protein levels correlated positively with plasma glucose concentration $(r=0.718, p<0.0001)$ (Fig. 6a). Similarly, PKC- $\beta$ I also correlated significantly with plasma glucose concentration $(r=0.779, p<0.0001)$ (Fig. 6b). The correlation of BBM levels of GLUT2 with PKC- $\beta$ I gave an $r$ value of 0.648 $(p<0.0001)$ (Fig. 6c).

\section{Discussion}

The present study shows clearly that changes in circulating glucose concentration can rapidly influence the levels of GLUT2 protein at the proximal tubule BBM. GLUTmediated transport activity at the BBM was also affected by activation of PKC and by increased cytosolic calcium. Protein levels of the calcium-dependent PKC isoform, PKC- $\beta$ I, correlated closely with the increase in GLUT2 and with plasma glucose concentration.

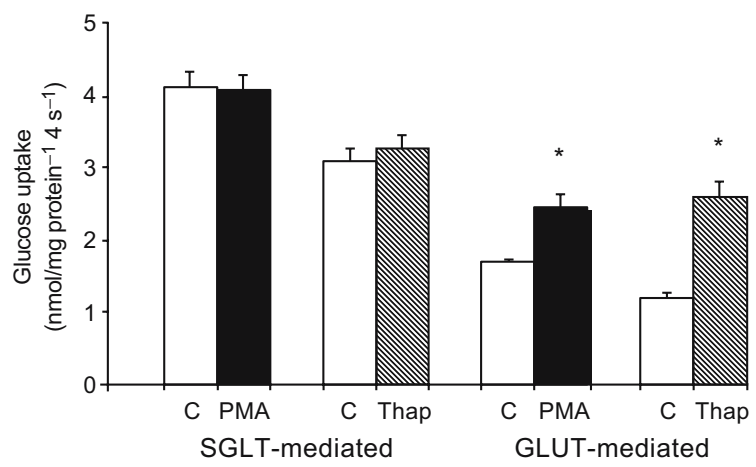

Fig. 3 Effect of PMA and thapsigargin on BBM vesicle glucose transport. $V_{\max }$ of SGLT-mediated transport was determined from uptakes measured at $30-960 \mu \mathrm{mol} / 1$ glucose and GLUT-mediated uptake was measured at $20 \mathrm{mmol} / 1$ glucose. Values are expressed as mean \pm SEM of six vesicle preparations. $* p<0.05$ compared with control using paired $t$ test. $C$ Control, Thap thapsigargin

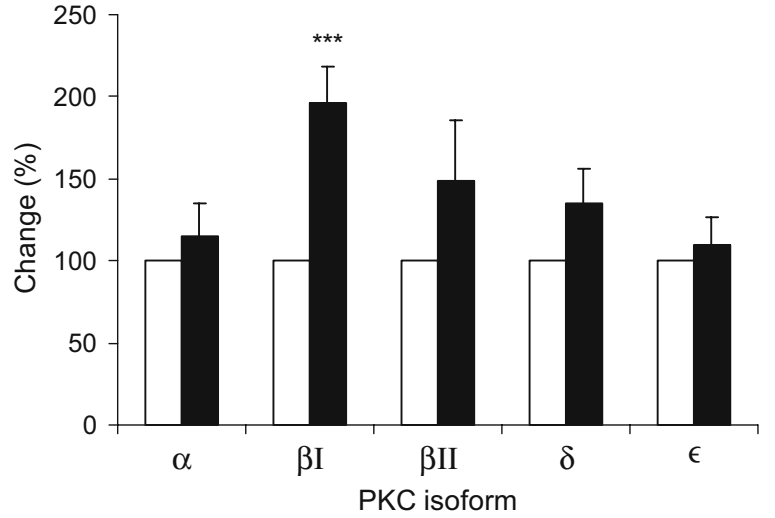

Fig. 4 Quantification of PKC isoforms in BBM vesicles of control (open bars) and STZ-treated (closed bars) animals. Results are expressed as a percentage compared with control, $n=6-12$. $* * * p<$ 0.001 compared with control using unpaired $t$ test

These findings are relevant to our understanding of the processes underlying diabetes-related changes in proximal tubular cell function. Although most studies have concentrated on the mechanisms of glucose-induced glomerular damage, there is evidence that tubular cell hypertrophy and basement membrane thickening are among the earliest pathological changes occurring in diabetes [19]. Tubulointerstitial fibrosis in diabetes is characterised by accumulation of extracellular matrix proteins, including fibronectin and collagen, leading eventually to tubulointerstitial scarring [20] and loss of tubular cell function. Unlike the glomerulus, exposure of human proximal tubular cells to elevated glucose levels does not affect collagen or fibronectin gene expression, but does result in a change in their degradation and rate of turnover [3, 21]. The tubulointerstitium comprises much of the kidney substance, and tubular hypertrophy is responsible for most of the renal

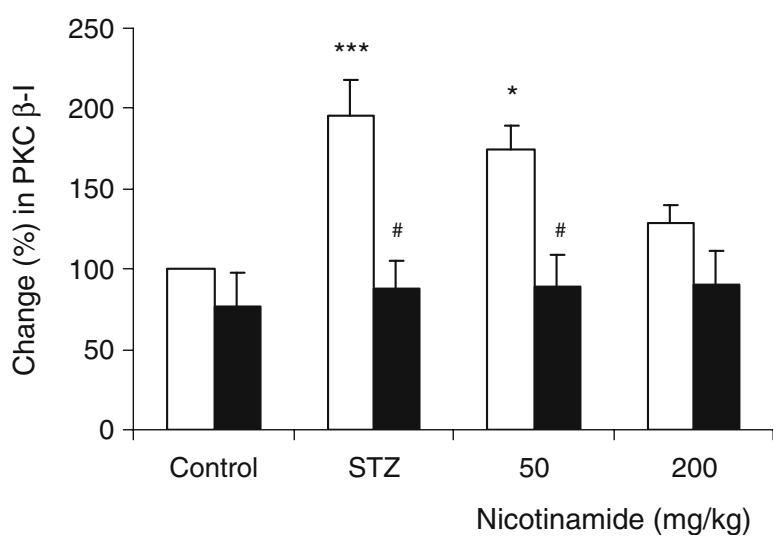

Fig. 5 Quantification of $\mathrm{PKC}-\beta \mathrm{I}$ in BBM vesicles of control and STZ-injected animals, with or without treatment with nicotinamide (open bars) or overnight (closed bars) fasting. Results are expressed as percentage change in PKC- $\beta \mathrm{I}$ expression compared with control, $n=6-12,{ }^{*} p<0.05, * * * p<0.001$ compared with non-fasted control animals using Kruskal-Wallis ANOVA; ${ }^{\#} p<0.05$ compared with nonfasted animals using unpaired $t$ test 

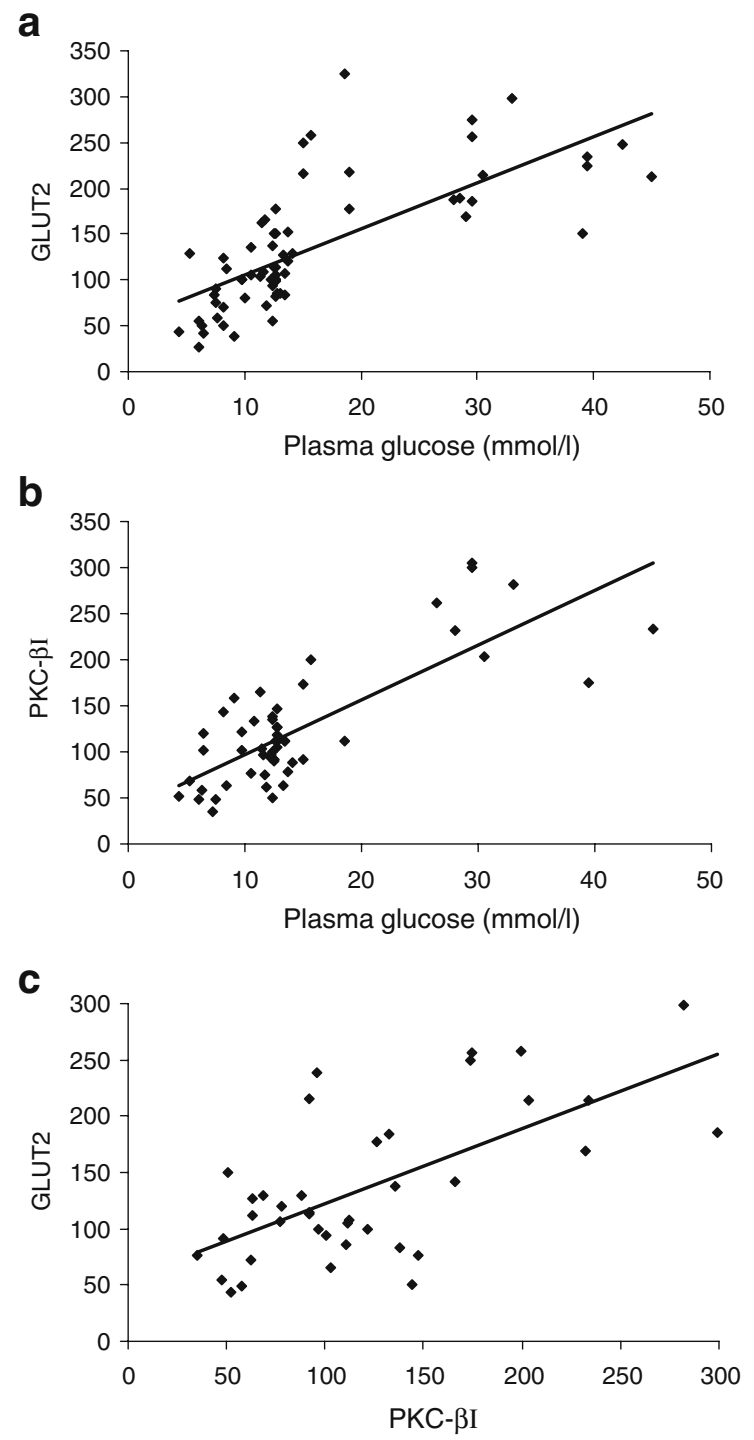

Fig. 6 Pearson's correlation between a GLUT2 protein levels and plasma glucose concentration, b PKC- $\beta I$ protein levels and plasma glucose concentration and $\mathbf{c}$ GLUT2 and PKC- $\beta$ I protein levels. $r=$ 0.718 (a), $r=0.779$ (b), $r=0.648$ (c); $p<0.0001$ (a-c)

enlargement seen in diabetes [4]. Although the transport mechanisms responsible for the increase in tubular glucose transport during diabetes (and therefore potentially the associated tubular hypertrophy) have been extensively studied, they have yet to be fully defined.

Studies focusing on the effect of diabetes on renal SGLTmediated glucose transport have yielded conflicting results, with reports of both increased [22] and decreased [23] rates of transport. Moreover, our previous study demonstrated that in STZ-induced diabetes the sodium-dependent component of renal glucose transport was unchanged, whereas the facilitative (GLUT-mediated) component was significantly enhanced. Western blotting showed an increase in both GLUT2 and GLUT5 protein at the BBM, with no change in GLUT1 protein levels; and that the upregulation of GLUT2, but not of GLUT5, could be abolished by overnight fasting [9]. Similar findings were reported by Freitas et al., who concluded that plasma glucose concentration was the key regulator of the gene encoding GLUT2 [24].

Our present results demonstrate that a reduction in plasma glucose concentration in STZ-diabetic rats treated with nicotinamide reduces STZ-induced renal hypertrophy, as well as GLUT2 protein levels. Therefore, since GLUT5 is considered to be a fructose transporter in vivo, with only a low affinity for glucose [25], and GLUT1 protein levels in the renal tubule are generally considered to be reduced [26, 27] or unchanged in diabetes [9], it is reasonable to hypothesise that GLUT2 might be responsible for glucose-induced tubular cell hypertrophy in diabetes. Indeed, two indirect findings also suggest a potential pathophysiological link between GLUT2 function and the kidney: one is the finding of renal hypertrophy and glomerulopathy in patients with GLUT2 mutations in the Fanconi-Bickel syndrome [28]; the other is the recent observation that flavonoids, which are known to ameliorate the changes of diabetic nephropathy in experimental models [29], inhibit GLUT2 production [30]. It is intriguing to speculate whether the beneficial effects of flavonoids in diabetes may be related, in part, to an inhibitory effect on GLUT2 in the kidney (and small intestine). Moreover, the DCCT showed the importance of tight control of blood glucose levels in preventing or delaying the onset of diabetic nephropathy [31], a finding with which our own may be consistent, since even modest elevations in plasma glucose concentration can affect GLUT2 levels at the BBM.

There is growing evidence that targeting SGLT-mediated renal glucose transport using phlorizin-like inhibitors may be useful in treating diabetes [32]. Two sodium-dependent transporters are produced in the kidney: the bulk of the filtered glucose is reabsorbed in the $\mathrm{S} 1$ segment by the lowaffinity, high-capacity transporter, SGLT2; whereas the high-affinity, low-capacity transporter, SGLT1, scavenges the remaining glucose more distally (reviewed in [17]). However, the predicted $K_{\mathrm{m}}$ values for these two transporters are 0.5 and $2 \mathrm{mmol} / 1$ for SGLT1 and SGLT2, respectively, and in the setting of a high filtered glucose concentration, as in uncontrolled diabetes, both transporters would be saturated. Therefore, GLUT2 in the kidney may be unregulated, as occurs in the small intestine [33], where high glucose concentrations 'sensed' by SGLT proteins lead to rapid insertion of GLUT2 into the BBM. With a predicted $K_{\mathrm{m}}$ of 20 to $40 \mathrm{mmol} / 1$ [17], GLUT2 would provide a capacity for glucose absorption that is much higher than that of the SGLT proteins. Thus, inhibitors of SGLT in diabetes may act by preventing this mechanism of GLUT2 upregulation and BBM targeting.

Substantial evidence now exists for a role of GLUT2 in the transport of glucose across the BBM of renal and 
intestinal epithelial cells. Although most studies have used the small intestine, the mechanisms controlling glucose uptake by proximal tubular cells display striking similarity to those occurring in enterocytes. In both cell types, activation of the protein kinase A signalling pathway increases intracellular cAMP levels and promotes SGLT1mediated glucose transport $[16,34]$. Short-term modulation of SGLT1-mediated transport occurs via apical membrane insertion of additional SGLT1 protein [35] and through changes in the membrane electrochemical gradient [16]. In enterocytes, activation of the PKC signalling pathway by PMA and the influx of $\mathrm{Ca}^{2+}$ through L-type channels have been shown to induce cytoskeletal re-arrangement, leading to insertion of GLUT2 protein at the BBM $[6-8,18,36]$.

There is less information on the regulation of GLUT2 in the kidney; however, our finding that incubation of isolated proximal tubules with PMA and thapsigargin increases GLUT-mediated, but not sodium-dependent glucose transport indicates that, as in the small intestine, PKC and calcium are potential signalling pathways regulating renal BBM GLUT2 protein levels. It has been reported that basal levels of cytosolic calcium in proximal tubule cells are elevated in rats with STZ-induced diabetes [37] and that high extracellular glucose increases cytosolic calcium in cultured proximal tubular cells by activation of L-type $\mathrm{Ca}^{2+}$ channels [38]. However, our results highlight one noticeable difference between the kidney and intestine. Thus, although in the kidney numerous PKC isoforms are detectable at the proximal tubule BBM, increased GLUT2 protein at the BBM is correlated only with increases in PKC- $\beta \mathrm{I}$; in the small intestine, by contrast, there is a strong correlation between the levels of GLUT2 and PKC- $\beta$ II [6, $18,36]$.

These differences in the PKC- $\beta$ isoforms responsible for regulation of GLUT2 in kidney and small intestine may be due to differential tissue production of these splice variants. In keeping with our findings, Hsieh et al. reported recently that glucose-induced damage to proximal tubule cells is dependent on PKC- $\beta$ I [14]. In addition, although there are conflicting results on which isoform(s) is(are) increased in the glomeruli of STZ-diabetic animals, with reports of increased levels of PKC- $\alpha$ [2, 10, 39], $-\beta \mathrm{I}[2,39,40],-\delta$ [41] and $-\varepsilon[10,41]$, PKC- $\beta$ I seems to be the pathophysiological isoform [40, 42]. Indeed, there is strong evidence that diabetes-induced mesangial cell damage occurs as a result of increased glucose uptake by GLUT1, which correlates with increased PKC- $\beta$ I activation and fibronectin and collagen accumulation [1]. Findings in the glomerulus, and our present findings, draw attention to the link between PKC activation and increased production of GLUT transporters in diabetes-induced renal damage.

Additional evidence that the PKC- $\beta$ I isoform is the predominant pathophysiological isoform in the kidney comes from studies using PKC- $\beta$-deficient $\left(P K C-\beta^{-1}\right)$ mice and the PKC- $\beta$ inhibitor, LY333531. Levels of the extracellular matrix proteins collagen and fibronectin, as well as those of the profibrotic cytokine TGF- $\beta$ are decreased in $P K C-\beta^{-/-}$mice; moreover, a significant reduction in renal hypertrophy and glomerular enlargement is seen when $P K C-\beta^{-/}$mice are made diabetic and compared with wild-type mice [39, 43]. Feeding of LY333531 to animals with STZ-induced diabetes has also been shown to prevent the increases in extracellular matrix components like fibronectin and collagen [2] and to reduce albuminuria and structural injury to the glomerulus $[40,42$, 44]. Interestingly, inhibition of PKC- $\beta$ by LY333531 also attenuated the diabetes-induced changes in the tubulointerstitium $[40,45]$. Clinical trials with LY333531, which is well tolerated [46, 47], indicate that it decreases albuminuria and maintains GFR [48], and can reduce microvascular complications in patients with diabetes $[49,50]$. Therefore, inhibition or lack of PKC- $\beta$ I production appears to protect against glucose-induced renal dysfunction and fibrosis.

In conclusion, we have demonstrated that raised circulating glucose levels promote targeting of GLUT2 protein to the proximal tubule BBM and that the levels of GLUT2 protein correlate with small changes in glucose concentration within the pathophysiological range. GLUT-mediated glucose uptake at the BBM is enhanced by PKC activation and an increase in cytosolic calcium; levels of GLUT2 and PKC- $\beta$ I in the BBM are also closely correlated. These findings highlight the potential significance of altered PKC$\beta I$ and GLUT2 in diabetic renal tubulopathy.

Acknowledgements We are grateful to the St Peter's Trust of the Middlesex Hospital for financial support.

Duality of interest The authors declare that there is no duality of interest associated with this manuscript.

\section{References}

1. Brosius FC, Heilig CW (2005) Glucose transporters in diabetic nephropathy. Pediatr Nephrol 20:447-451

2. Koya D, Jirousek MR, Lin YW, Ishii H, Kuboki K, King GL (1997) Characterization of protein kinase C beta isoform activation on the gene expression of transforming growth factorbeta, extracellular matrix components, and prostanoids in the glomeruli of diabetic rats. J Clin Invest 100:115-126

3. Phillips AO, Morrisey K, Steadman R, Williams JD (1999) Decreased degradation of collagen and fibronectin following exposure of proximal cells to glucose. Exp Nephrol 7:449-462

4. Nath KA (1992) Tubulointerstitial changes as a major determinant in the progression of renal damage. Am J Kidney Dis 20:1-17

5. Helliwell PA, Rumsby MG, Kellett GL (2003) Intestinal sugar absorption is regulated by phosphorylation and turnover of protein kinase $\mathrm{C}$ betaII mediated by phosphatidylinositol 3-kinase and mammalian target of rapamycin-dependent pathways. J Biol Chem 278:28644-28650 
6. Morgan EL, Mace OJ, Helliwell PA, Affleck J, Kellett GL (2003) A role for $\mathrm{Ca}(\mathrm{v}) 1.3$ in rat intestinal calcium absorption. Biochem Biophys Res Commun 312:487-493

7. Morgan EL, Mace OJ, Affleck JA, Kellett GL (2007) Apical GLUT2 and Cav1.3: regulation of rat intestinal glucose and calcium absorption. J Physiol 580:593-604

8. Mace OJ, Morgan EL, Affleck JA, Lister N, Kellett GL (2007) Calcium absorption by Cav1.3 induces terminal web myosin II phosphorylation and apical GLUT2 insertion in rat intestine. J Physiol 580:605-616

9. Marks J, Carvou NJ, Debnam ES, Srai SK, Unwin RJ (2003) Diabetes increases facilitative glucose uptake and GLUT2 expression at the rat proximal tubule brush border membrane. J Physiol 553:137-145

10. Kang N, Alexander G, Park JK et al (1999) Differential expression of protein kinase $\mathrm{C}$ isoforms in streptozotocin-induced diabetic rats. Kidney Int 56:1737-1750

11. Dong LQ, Stevens JL, Jaken S (1991) Biochemical and immunological characterization of renal protein kinase C. Am J Physiol 261:F679-F687

12. Pfaff IL, Wagner HJ, Vallon V (1999) Immunolocalization of protein kinase $\mathrm{C}$ isoenzymes alpha, betal and betaII in rat kidney. J Am Soc Nephrol 10:1861-1873

13. Redling S, Pfaff IL, Leitges M, Vallon V (2004) Immunolocalization of protein kinase $\mathrm{C}$ isoenzymes alpha, beta I, beta II, delta, and epsilon in mouse kidney. Am J Physiol Renal Physiol 287:F289-F298

14. Hsieh TJ, Chen R, Zhang SL et al (2006) Upregulation of osteopontin gene expression in diabetic rat proximal tubular cells revealed by microarray profiling. Kidney Int 69:1005-1015

15. Masiello P, Broca C, Gross R et al (1998) Experimental NIDDM: development of a new model in adult rats administered streptozotocin and nicotinamide. Diabetes 47:224-229

16. Sharp PA, Debnam ES (1994) The role of cyclic AMP in the control of sugar transport across the brush-border and basolateral membranes of rat jejunal enterocytes. Exp Physiol 79:203-214

17. Debnam ES, Unwin RJ (1996) Hyperglycemia and intestinal and renal glucose transport: implications for diabetic renal injury. Kidney Int 50:1101-1109

18. Helliwell PA, Richardson M, Affleck J, Kellett GL (2000) Stimulation of fructose transport across the intestinal brush-border membrane by PMA is mediated by GLUT2 and dynamically regulated by protein kinase C. Biochem J 350:149-154

19. Ziyadeh FN (1993) The extracellular matrix in diabetic nephropathy. Am J Kidney Dis 22:736-744

20. Norman JT, Fine LG (1999) Progressive renal disease: fibroblasts, extracellular matrix, and integrins. Exp Nephrol 7:167-177

21. Phillips AO, Steadman R, Morrisey K, Martin J, Eynstone L, Williams JD (1997) Exposure of human renal proximal tubular cells to glucose leads to accumulation of type IV collagen and fibronectin by decreased degradation. Kidney Int 52:973-984

22. Blank ME, Bode F, Huland E, Diedrich DF, Baumann K (1985) Kinetic studies of D-glucose transport in renal brush-border membrane vesicles of streptozotocin-induced diabetic rats. Biochim Biophys Acta 844:314-319

23. Yasuda H, Kurokawa T, Fujii Y, Yamashita A, Ishibashi S (1990) Decreased D-glucose transport across renal brush-border membrane vesicles from streptozotocin-induced diabetic rats. Biochim Biophys Acta 1021:114-118

24. Freitas HS, D'Agord SB, da Silva RS, Okamoto MM, OliveiraSouza M, Machado UF (2007) Insulin but not phlorizin treatment induces a transient increase in GLUT2 gene expression in the kidney of diabetic rats. Nephron Physiol 105:42-51

25. Miyamoto K, Tatsumi S, Morimoto A et al (1994) Characterization of the rabbit intestinal fructose transporter (GLUT5). Biochem J 303:877-883
26. Dominguez JH, Camp K, Maianu L, Feister H, Garvey WT (1994) Molecular adaptations of GLUT1 and GLUT2 in renal proximal tubules of diabetic rats. Am J Physiol 266:F283-F290

27. Kamran M, Peterson RG, Dominguez JH (1997) Overexpression of GLUT2 gene in renal proximal tubules of diabetic Zucker rats. J Am Soc Nephrol 8:943-948

28. Santer R, Schneppenheim R, Suter D, Schaub J, Steinmann B (1998) Fanconi-Bickel syndrome - the original patient and his natural history, historical steps leading to the primary defect, and a review of the literature. Eur J Pediatr 157:783-797

29. Kamalakkannan N, Stanely Mainzen PP (2006) The influence of rutin on the extracellular matrix in streptozotocin-induced diabetic rat kidney. J Pharm Pharmacol 58:1091-1098

30. Kwon O, Eck P, Chen S et al (2007) Inhibition of the intestinal glucose transporter GLUT2 by flavonoids. FASEB J 21:366-377

31. The Diabetes Control and Complications Trial Research Group (1993) The effect of intensive treatment of diabetes on the development and progression of long-term complications in insulin-dependent diabetes mellitus. N Engl J Med 329:977-986

32. Wright EM, Hirayama BA, Loo DF (2007) Active sugar transport in health and disease. J Intern Med 261:32-43

33. Kellett GL (2001) The facilitated component of intestinal glucose absorption. J Physiol 531:585-595

34. Marks J, Debnam ES, Dashwood MR, Srai SK, Unwin RJ (2003) Detection of glucagon receptor mRNA in the rat proximal tubule: potential role for glucagon in the control of renal glucose transport. Clin Sci (Lond) 104:253-258

35. Williams M, Sharp P (2002) Regulation of jejunal glucose transporter expression by forskolin. Biochim Biophys Acta 1559:179-185

36. Kellett GL, Helliwell PA (2000) The diffusive component of intestinal glucose absorption is mediated by the glucose-induced recruitment of GLUT2 to the brush-border membrane. Biochem J 350:155-162

37. Marcinkowski W, Zhang G, Smogorzewski M, Massry SG (1997) Elevation of $\left[\mathrm{Ca}^{2+}\right]_{\mathrm{i}}$ of renal proximal tubular cells and downregulation of mRNA of PTH-PTHrP, V1a and AT1 receptors in kidney of diabetic rats. Kidney Int 51:1950-1955

38. Park SH, Choi HJ, Lee JH, Yang IS, Han HJ (2001) High glucose stimulates $\mathrm{Ca}^{2+}$ uptake via cAMP and PLC/PKC pathways in primary cultured renal proximal tubule cells. Kidney Blood Press Res 24:10-17

39. Ohshiro Y, Ma RC, Yasuda Y et al (2006) Reduction of diabetesinduced oxidative stress, fibrotic cytokine expression, and renal dysfunction in protein kinase C beta-null mice. Diabetes 55:31123120

40. Kelly DJ, Zhang Y, Hepper C et al (2003) Protein kinase C beta inhibition attenuates the progression of experimental diabetic nephropathy in the presence of continued hypertension. Diabetes 52:512-518

41. Ha H, Yu MR, Choi YJ, Lee HB (2001) Activation of protein kinase c-delta and c-epsilon by oxidative stress in early diabetic rat kidney. Am J Kidney Dis 38:S204-S207

42. Koya D, Haneda M, Nakagawa $H$ et al (2000) Amelioration of accelerated diabetic mesangial expansion by treatment with a PKC beta inhibitor in diabetic $d b / d b$ mice, a rodent model for type 2 diabetes. FASEB J 14:439-447

43. Meier M, Park JK, Overheu D et al (2007) Deletion of protein kinase $\mathrm{C}$ - $\{$ beta $\}$ isoform in vivo reduces renal hypertrophy but not albuminuria in the streptozotocin-induced diabetic mouse model. Diabetes 56:346-354

44. Haneda M, Koya D, Kikkawa R (2001) Cellular mechanisms in the development and progression of diabetic nephropathy: activation of the DAG-PKC-ERK pathway. Am J Kidney Dis 38:S178-S181 
45. Wu Y, Wu G, Qi X et al (2006) Protein kinase C beta inhibitor LY333531 attenuates intercellular adhesion molecule-1 and monocyte chemotactic protein-1 expression in the kidney in diabetic rats. J Pharmacol Sci 101:335-343

46. McGill JB, King GL, Berg PH et al (2006) Clinical safety of the selective PKC-beta inhibitor, ruboxistaurin. Expert Opin Drug Saf 5:835-845

47. Shen GX (2003) Selective protein kinase C inhibitors and their applications. Curr Drug Targets Cardiovasc Haematol Disord 3:301-307
48. Tuttle KR, Bakris GL, Toto RD, McGill JB, Hu K, Anderson PW (2005) The effect of ruboxistaurin on nephropathy in type 2 diabetes. Diabetes Care 28:2686-2690

49. Avignon A, Sultan A (2006) PKC-B inhibition: a new therapeutic approach for diabetic complications? Diabetes Metab $32: 205-213$

50. Joy SV, Scates AC, Bearelly S et al (2005) Ruboxistaurin, a protein kinase $\mathrm{C}$ beta inhibitor, as an emerging treatment for diabetes microvascular complications. Ann Pharmacother 39:1693-1699 